\title{
EXPERIÊNCIA CLÍNICA POR MEIO DE IMAGENS CARTOGRÁFICAS
}

\author{
CLINICAL EXPERIENCE THROUGH CARTOGRAPHIC IMAGES
}

\author{
Janayna Araújo Costa Pinheiro e Leila Domingues Machado \\ Universidade Federal do Espírito Santo, Vitória, Brasil
}

\begin{abstract}
Resumo
$\mathrm{O}$ artigo refere-se à pesquisa "Cartografia por imagens em uma experiência clínica", que buscou acompanhar os trajetos cotidianos dos moradores de dois Serviços Residenciais Terapêuticos, localizados num bairro de periferia da Grande Vitória. Consideramos tais percursos como efeitos do Dispositivo-Casa - Serviço Residencial Terapêutico. Por meio desse dispositivo tem sido possível ampliar a rede de atenção à saúde, indo além dos ditos serviços de atenção. Abre-se, a partir dessas caminhadas, uma discussão sobre o que temos chamado de clínica e rede de atenção em saúde mental, bem como se questionam as nossas contribuições como profissionais de saúde. Para tanto, buscamos em Deleuze e Guattari uma articulação da perspectiva cartográfica com a experiência clínica para dar visibilidade aos movimentos que expressam e produzem encontros, imprevistos e experiências, deslocando as produções subjetivas estabelecidas.
\end{abstract}

Palavras-chave: clínica; subjetividade; saúde mental; cartografia.

\begin{abstract}
The article refers to the research entitled "Cartography through images in a clinical experience", which meant to follow the daily walks of residents of two Therapeutic Residential Services located in the metropolitan area of Vitória. We considered these paths as effects of this Device-House-Therapeutic Residential Service. Such device has made possible the enlargement of the health attention network, going beyond the attention services. These walks allow a discussion on what we have come to call clinic and attention network on mental health, as well as questioning how have we contributed as health professionals. For this, we searched in the work of Deleuze and Guattari an articulation of the cartographic perspective with the clinical experience in order to give visibility to movements that express and cause meetings, unexpected situations and experiences, dislocating the established subjective productions.
\end{abstract}

Keywords: clinic; subjectivity; mental health; cartography.

Este artigo visa relatar questionamentos levantados na dissertação "Cartografia por imagens em uma experiência clínica", desenvolvida no Programa de Mestrado em Psicologia Institucional da Universidade Federal do Espírito Santo (UFES). A pesquisa foi realizada no período de 2007 a 2008 e teve como objetivo acompanhar por meio de filmagens os trajetos percorridos pelos moradores dos dois primeiros Serviços Residenciais Terapêuticos (SRT) do Estado do Espírito Santo, localizados no bairro Santana, município de Cariacica, Grande Vitória.

\section{Dispositivo-Casa}

Os Serviços Residenciais Terapêuticos foram criados pelo governo a partir da Portaria GM n. ${ }^{\circ}$ $106 / 00$, com a finalidade de receber pessoas internadas em hospital psiquiátrico por mais de dois anos consecutivos e sem vínculos familiares. Esses serviços são prioritariamente instalados em "municípios onde já existam outros serviços ambulatoriais de saúde mental de natureza substitutiva aos hospitais psiquiátricos" (Portaria n. 106, 2000, art. $9^{\circ}$ ).

Os SRT ou Dispositivos-Casa (como preferimos chamá-los) são, portanto, moradias e têm como propósito a inserção de pessoas no ambiente da vida. Apostamos que as Casas funcionam como disparadoras de interferências visíveis e invisíveis nos modos de vida dos moradores, cuidadores, vizinhos, estabelecimentos (padaria, farmácia, bares etc.), bairro, comunidade, cidade etc. (Lavrador, 2006).

Nesse sentido, as Casas podem funcionar como espaço de transição, pois o morador pode sair da Casa para ir morar sozinho ou simplesmente circular no es- 
paço da cidade. Assim, pensamos que uma saída pode funcionar também como disparador, o que nos convocou a refletir sobre os efeitos da estratégia Dispositivo-Casa.

No Espírito Santo, as primeiras Casas foram organizadas em 2004, sendo uma masculina e outra feminina, cada uma acolhendo até oito moradores. No estado, até o momento da pesquisa, havia cinco Casas, localizadas em Cariacica, na região da Grande Vitória [1].

Para conhecer os efeitos do Dispositivo-Casa, acompanhamos os movimentos dos moradores das duas primeiras Casas criadas no bairro, escolhidas por serem as mais antigas e pelo acesso por meio do Hecceidades: programa de pesquisa-intervenção em saúde mental [2].

Para andar junto com os moradores das Casas nas ruas do bairro, juntamo-nos ao grupo de estagiários composto por estudantes de graduação em psicologia da UFES. Inserimo-nos na rotina do estágio - troca de e-mails, supervisões, conversas informais etc. - e no movimento de "saída" do grupo.

Em nossa experiência, para acompanhar o processo de mudanças subjetivas nos trajetos das pessoas no bairro onde vivem, realizamos procedimentos como frequentar o bairro durante um período de dez meses, de agosto de 2007 a maio de 2008 - uma ida por semana nos cinco primeiros meses e nos cinco últimos - com uma visita a cada quinze dias.

As idas ao bairro visaram ao conhecimento do campo, proporcionando a familiaridade com o movimento, com o ambiente e com as pessoas. Assim, essas incursões alcançaram os Serviços Residenciais Terapêuticos, o Centro de Atenção Psicossocial de referência e os estabelecimentos comerciais.

Foi-se ao banco, ao INSS, ao CAPS, à padaria; visitaram-se outras Casas, caminhou-se e passeou-se no Shopping Center, na praia etc. Algumas dessas saídas deram-se em grupo e outras, individualmente; algumas foram realizadas com os estagiários, outras, sem eles. Algumas combinações de saídas foram mais recorrentes; outras, mais esporádicas; os trajetos recorrentes levam ao CAPS, onde se cumpre um projeto terapêutico [3]; promovem-se deslocamentos para outras Casas e para estabelecimentos comerciais e não comerciais dentro do próprio bairro. As saídas mais esporádicas são combinações com os estagiários: à praia, ao parque, ao shopping, ao teatro etc.

As saídas que acompanhamos compõem-se das combinações mais recorrentes, mais presentes na rotina da Casa, como os deslocamentos até o CAPS, mas contemplam também as saídas conquistadas ao longo do período de convivência com o bairro, como as idas à padaria, à barbearia ou ao salão de beleza, à praça, ao supermercado, à unidade de saúde, visitas a outra Casa etc. São percursos que alguns moradores realizam sozinhos e se constituíram para além dos serviços de saúde. Tais andanças formaram os caminhos percorridos por esta pesquisa.

Interessou-nos conhecer os efeitos da presença das Casas na comunidade: que relações de interação elas construíram até o momento? A aposta era que já havia processos em transformação junto à comunidade, mas quais? Como seriam? Para acompanhar essas transformações, estivemos ao lado dos moradores nas saídas e, para compor a pesquisa, utilizamos as informações produzidas nos trajetos já percorridos.

Dos trajetos participaram principalmente o pesquisador e um ou dois moradores da Casa. No entanto, algumas saídas contaram com a participação de mais de quatro moradores, bem como de estagiários do Hecceidades. Depois de cada saída, ocupamo-nos em registrar a experiência vivida, de modo que as anotações posteriormente nos servissem como fonte de informações para a análise.

Diante dos movimentos da pesquisa, outra questão logo se fez presente: o que estamos chamando de saída? Não era intenção reduzir as saídas a "passeios", pois nem todas as saídas são passeios. Portanto, para onde nos leva o fora do espaço fechado das casas e prédios? Consideramos a cidade, o bairro e o que se oferece de exterioridade (Caiafa, 2005): as praças, as ruas, praias etc.

Em um primeiro momento, pensamos essa exterioridade como algo além dos espaços fechados de atendimentos e serviços de atenção à saúde. Entre os estagiários, havia uma problemática que se aproximava dessa primeira ideia: como se escapa dos movimentos de controle e dominação? Até que ponto as saídas colaboram? Que contribuições podemos oferecer?

Ao conhecer a rotina das Casas, atentamos para o fato de que os trajetos já eram, de uma forma ou de outra, familiares, mas havia neles algumas singularidades. Por um lado, alguns moradores apresentavam dificuldades físicas para se locomover, o que inibia saídas mais frequentes e os fazia permanecer mais tempo nas Casas; por outro lado, outros moradores saíam com mais frequência.

Problematizamos o termo "saída" e buscamos uma ampliação do seu sentido. O que estamos chamando de saída não se reduz ao deslocamento de um ambiente fechado para outro a céu aberto. Segundo Houaiss (2004, p. 660), saída é o "ato de sair ou o seu efeito; lugar por onde se sai; momento em que se sai; meio para sair de um apuro, recurso, expediente; resposta ou observação feliz, espirituosa, escapatória".

Assim, em um segundo momento, questionamos se a exterioridade seria necessariamente o fora de um estabelecimento ou se já se constituía frente aos acontecimentos da vida. De todo modo, a pesquisa se ocupou 
com a situação de acompanhar os moradores fora das Casas e não buscou criar outros e novos trajetos, para assim poder cartografar os caminhos próprios, ou seja, o entrelaçamento das subjetivações.

A saída nos remete aos seus efeitos. A experiência de saída se dá no ato, como também por meio de uma "resposta espirituosa". Dessa maneira, constatamos vários modos de saída, que não se referem somente ao ato ou momento de sair de algum lugar, mas também à "saída" de uma determinada situação de apuro, bem como à "saída" por resposta espirituosa. Em uma conversa em que se é levado a dizer ou agir de modo improvisado, pode surgir uma boa saída. Podemos sair de situações, e não só de lugares.

No caso dos moradores das Casas, uma saída já aconteceu: de um hospital psiquiátrico - situação de encarceramento - para uma casa. Assim, ao acompanharmos os trajetos já percorridos, priorizamos os caminhos trilhados no bairro, diferentes daqueles praticados entre os serviços de saúde.

Habitar nossas casas implica também habitar as ruas, as praças, as padarias, enfim, todos os lugares que frequentamos. Delimitamos o campo geográfico da pesquisa: o bairro, como um espaço dentro da noção de cidade, constituindo-se como intensa fonte de informações e de viva produção de dados, o que nos permitiu pensar sobre os efeitos do ato de sair, ou seja, sobre as produções que emergem nessa paisagem psicossocial.

\section{Cartografia-fílmica}

Para acompanhar os moradores das Casas, utilizamos o processo cartográfico. A cartografia é conhecida como uma prática do campo da geografia que trata da concepção, produção, difusão, utilização e estudo dos mapas e representação de territórios geográficos. Em nosso caso, interessa a ação que precede essa produção, a prática cartográfica no terreno psicossocial. Utilizamos essa noção para acompanhar as produções de subjetividades.

Então, a cartografia seria um método de pesquisa? Depende. Pensamos que a cartografia não é nem uma descrição a posteriori do processo de pesquisa, nem um programa de regulação definido a priori. Para pensarmos a cartografia como método de pesquisa, precisamos conceber o método como construção ético-estético-política que se faz no processo da pesquisa. Isso porque se recurvarmos a cartografia para que se adapte aos sentidos convencionais de método, já não estaremos fazendo cartografia, e sim outra coisa. Então, Precisamos forçar a concepção de método a se recurvar, a assumir outros sentidos, a conceber outras formas de pesquisar, outras vertentes de pesquisa, outros compromissos para o pesquisador. Assim, permitimos que a cartografia continue sendo cartografia e impulsionamos o método e a metodologia a se recriarem frente aos novos desafios que se impõem. (Machado, 2008b, p. 48)

Nesse sentido, ao cartografar, apostamos em algumas atitudes frente às situações existenciais (sentimentos, sensações, lembranças e falas) e atentamos para os fluxos de forças que cruzam certo espaço de tempo e lugar no território existencial. Entende-se por território, em um sentido mais amplo, como "relativo tanto ao espaço vivido, quanto a um sistema percebido no seio do qual um sujeito se sente "em casa" (Guattari \& Rolnik, 2005, p. 388). Ou seja, não se restringe à noção espaço-geográfica. Desse modo, buscamos em Deleuze e Guattari algumas pistas para cartografar. [4]

A cartografia demanda a dissolução da linha divisória sujeito-objeto para que ambos, sujeito e objeto, se deixem atravessar pelas linhas de visibilidade, de invisibilidade, de silêncio, de dizibilidade, de sombras, de força e de enunciação na produção de subjetividades. O pesquisador-cartógrafo estará impregnado com suas próprias cenas, mas também será como estrangeiro, ao percorrer um roteiro ainda não conhecido. De todo modo, entendemos ser prudente seguir alguns procedimentos iniciais para a construção do processo, tais como ir até o local, delimitar um terreno, conhecê-lo, buscar suas variações, nuanças e tensões.

Interessou-nos acompanhar a produção de movimentos e a construção de espaços onde experiências e modos de existência se encontram e produzem outras experiências e outros modos de existência, que provocam (ou não) deslocamentos das produções de subjetividades estabelecidas.

Para acompanhar os efeitos dos encontros nas ruas, investimos em outro recurso de intervenção, além de estar ao lado e andar junto com os moradores. Consideramos o uso de uma filmadora como ferramenta para a cartografia, tomando como referência as experiências de filmagens já realizadas no Hecceidades, bem como experiências de âmbito nacional conhecidas, como a Rádio TAM TAM e a TV Pinel.

Apesar de o recurso acompanhar o movimento contínuo, ele não capta tudo. É preciso considerar que o vídeo é sempre o registro a partir de um olhar, a imagem é vista de certo ângulo com um recorte retangular. E além disso, com a edição, certas imagens são suprimidas: com a conclusão do vídeo, não estarão nele todas as imagens capturadas. As imagens - ou o mapa-movimento - funcionaram tanto como registro quanto como documento da pesquisa. Ao registrar-se a ação, ela própria torna-se documento. Contudo, o vídeo cartográfico diz de uma parte do percurso da pesquisa. Neste artigo não nos deteremos no detalhamento e na construção dessa ferramenta.

Entretanto, vale salientar que cada um responde de uma forma à experiência de filmagem: algumas 
pessoas ficam à vontade, outras até mesmo interagem com a câmera, enquanto outras preferem não ser filmadas. Dentro desse contexto, a opção foi filmar somente aquelas que autorizaram tal procedimento. A autorização ocorreu tanto verbalmente quanto por meio de Termo de Consentimento Livre e Esclarecido (TCLE). A proposta da pesquisa foi previamente explicada e somente depois de um período de cerca de cinco meses frequentando o bairro com os moradores é que se deu início aos registros fílmicos.

Percorremos os trajetos dos moradores no próprio bairro: atravessamos ruas, avenidas, calçadas, fomos à praça, à padaria, à barbearia, ao supermercado, ao CAPS, cumprimentamos e fomos cumprimentados, conversamos etc. Assim, o processo cartográfico permitiu a observação de nuanças e tensões na paisagem psicossocial. Salientaremos aqui três situações [5] que nos ajudarão a pensar sobre a experiência clínica.

\section{Clínica entre parênteses}

A clínica, no âmbito da saúde mental, se faz no processo de desinstitucionalização, ou seja, no trabalho diário dos técnicos que têm o poder de dinamizar e potencializar a mudança de paradigma. A desinstitucionalização se dá o tempo todo e não se limita ao processo de reforma: expande-se ao trabalho clínico e põe em análise as práticas de dominação que o atravessam.

Segundo Rotelli, Leonardis e Mauri (1990, p. 32), a desconstrução consiste, concretamente, em "reconstituir o direito e a capacidade de uso dos objetos pessoais; reconstruir o direito e a capacidade de palavra; ... abrir as portas; produzir relações, espaços e objetos de interlocução". Esse é um trabalho em ato contínuo de reduzir o poder cronificador e desabilitante dos tratamentos tradicionais.

A clínica pode estar presente como força disruptiva e se intensificar quando somada a outras atividades. No dia a dia do trabalho, o profissional ora cumpre os atendimentos clássicos, ora se envolve em situações nas quais nem imaginava estar presente, construindo samba-enredo, montando desfile de moda, indo ao shopping ou à praia, caminhando ao lado ou indo ao encontro do outro etc. É recorrente a mistura dessa clínica com outros campos do saber, como artes, comunicação, teatro, música e assim por diante. E por que não pensar a partir desse hibridismo as experiências com a clínica?

Nas imbricações da clínica com outros saberes forjamos mutações nos processos de subjetivações e ao mesmo tempo somos provocados a pensar em como tais processos podem se desviar da lógica de captura e criar outros caminhos, outros encontros. Cabe a nós pensar sobre o que temos feito da experiência cotidiana, se não a estamos reduzindo a um fazer sem pensar.
A reflexão sobre a construção da prática clínica junto ao processo da reforma nos situa frente às possibilidades de criar outras formas de atuar e perguntar: de que clínica estamos falando? Como vem sendo forjada? Como acompanhar o fluxo da vida presente no cotidiano? É preciso estar atento aos pequenos movimentos para acompanhar as linhas dos dispositivos em formação que ora emergem, ora se desfazem.

Na medida em que a atenção à saúde tem como perspectiva a complexidade da relação do sujeito com seu sofrimento psíquico e não mais o sintoma ou a doença, o profissional de saúde precisa usar outras estratégias, ocupar outros espaços e apostar em outras abordagens, como nos encontros que acontecem no corredor, nas festas, nas ruas, nas idas e vindas à praia.

Essas situações passíveis de intervenções acontecem dentro e fora dos serviços e abrem vistas a outra estratégia clínica que inclui os atendimentos individuais, mas não se restringe a eles, expandindo-se a atendimentos em grupo, participação em feiras, realizações de oficinas, movimentos comemorativos, participação nos blocos de carnaval, caminhadas, visitas familiares etc.

Nesse sentido, pensar os efeitos produzidos pelos Serviços Residenciais Terapêuticos, considerando-os disparadores de ações e de acontecimentos para fora de seus espaços estabelecidos, é apostar que no contexto da vida, em que se constroem modos de estar no mundo e de conviver com o que ele oferece, estabelece-se um campo para se pensar a clínica e ampliar a rede de atenção à saúde.

Os moradores das Casas vivem, hoje, fora dos muros do hospital. São homens e mulheres que desafiam a vida exercitando a liberdade do ir e vir, não sem impasses, mas enfrentando outras possibilidades de existência. Não cremos ingenuamente que por estarem fora do hospital estejam imunes a capturas manicomiais. É preciso sempre questionar nossas práticas, a fim de não repetir o modelo clássico, de não convocá-los a repetir nosso cotidiano, visto que esse risco se apresenta para todos e qualquer um.

Essa questão ganha relevo ao reforçarmos o "novo", já discutido desde os primeiros serviços (Amarante et al., 2001) e constitui um alerta constante. Os "novos" serviços não são apenas um "novo espaço" para a loucura. O "novo" está na ruptura com o paradigma doença-cura. $\mathrm{O}$ fato de ocupar o tempo com atividades artesanais ou recreativas ou de oferecer um lugar para passar o dia não garante que se faça clínica.

É preciso questionar se conseguimos manter o aspecto inovador ou se reproduzimos o modelo clássico. Levantar essa questão nos permite problematizar o fazer ético-político diante da experiência da loucura. O retorno à atividade produtiva pode caracterizar uma prática 
tão excludente e controladora quanto qualquer hospital psiquiátrico (Yasui, 1989). No entanto, a desmontagem dessa lógica só é possível na relação. É na experiência que se percebe a possibilidade de mudança.

Entendemos a clínica como uma instituição, na medida em que pressupõe uma forma de fazer clínica. Analisá-la implica questionarmos o que afirmamos sobre a clínica, o que estamos construindo e que caminhos produzimos. Nesse sentido, analisar o fazer-saber clínico torna-se uma prerrogativa. A clínica é também uma instituição em processo de desinstitucionalização, e cabe desconstruir esse conceito. "A desconstrução enquanto tal não se reduz nem a um método (redução ao simples) nem a uma análise; ela vai além da decisão crítica, da própria ideia de crítica" (Derrida, 1990, citado por Amarante, 2003, p. 50).

As intervenções para ativar esse processo não são uma simples aplicação de novas técnicas ou terapias, implicando a construção de outro modo de estar na situação. Se as relações são produzidas a partir da lógica doença-cura, é na ruptura desse paradigma que se passa à clínica, considerando que tal ruptura não se dá de um dia para o outro, mas como "um processo complexo de recolocar o problema, de reconstruir saberes e práticas, de estabelecer novas relações" (Amarante, 2003, p. 50).

\section{Cena 1}

Para chegar a um mesmo lugar havia vários itinerários, sendo uns mais curtos, outros mais longos. $\mathrm{O}$ tráfego no bairro era intenso, e percebemos o cuidado dos moradores entre si e para conosco. Por vezes, ouvimos um e outro chamarem nossa atenção para um carro ou caminhão que passava: "Cuidado o carro! Cuidado o carro!", "Olha o caminhão ai!!".

Da análise dessa cena surge a pergunta: quem cuida de quem? Problematizar a palavra cuidador [6] convocou-nos a avaliar nossa contribuição. Como pensar a clínica nesse contexto? Cuidador é "aquele que cuida, quem trata, toma conta de (alguém ou algo)" (Houaiss \& Villar, 2001).

Para continuar a reflexão, voltemos à situação que nos convocou a pensar sobre tal questão. Retomemos a fala dos moradores, ouvida enquanto andávamos no bairro: "Cuidado o carro!" e "Olha aí o caminhão!". Se a palavra cuidador remete àquele que cuida, então alguém cuida. Quem é ele? Aquele que fala, o que escuta, ou ambos?

Em nossa experiência, a fala exprimiu uma advertência, dirigida a nós em relação ao carro ou caminhão. Mas não foram somente advertências que ouvimos e vimos, o cuidado implicou "prestar atenção em, preocupar-se com, responsabilizar-se por". Nossa questão então se expande: por onde passa o cuidado?
Se o cuidador é "aquele que cuida" e o cuidado vem daquele que se pronuncia, podemos considerar que "aquele que cuida" pode ser qualquer um de nós. Talvez a ideia de cuidador não se prenda a uma ou outra pessoa. Todavia, é preciso cautela, pois a noção de cuidador pode se ampliar e esbarrar na de tutela.

Exercemos o cuidado ou temos que cuidar como um puro "tomar conta" técnico, como se houvesse um modo cuidador de agir estabelecido? Há uma forma-cuidado a ser apreendida e aplicada? Talvez seja possível pensar em uma noção de cuidador e considerar as variáveis e diversidades de modos de ser cuidador.

Entretanto é preciso "pensar, prestar atenção, preocupar-se, olhar, ter atenção para consigo [e/ou com o outro]" ao cuidar; pois o mesmo cuidado pode estar muito próximo do "tomar conta", em estreita fronteira com a tutela, posição que se repete entre nós.

O cuidador cuida, e o faz com cuidado. E isso não deve se confundir com obediência, subordinação ou submissão imposta por alguém ou algo mais poderoso. Cuidadores, quem somos?

\section{Cena 2}

Entre um passo e outro, e imersos no silêncio do compasso, irrompe um comentário: "Eles me chamam de Robocop!", "Quem?", "Esse pessoal ai", "Por quê?". $\mathrm{E}$ a resposta de quem não quer falar para além do que já foi dito: "Ojeito de andar ... O jeito de eu andar, por isso". O silêncio foi interrompido sem que nenhuma pergunta do pesquisador provocasse a interrupção. $\mathrm{O}$ dito irrompeu, e pronto.

O jeito de andar marca um tempo-movimento. No passo-a-passo produzimos um equilíbrio-desequilíbrio, e o caminhar ganha relevo. Não é em um continuum que vivemos.

Com perguntas e respostas curtas, que conversas é possível produzir? Até que ponto insistimos com a história? Até que ponto escutamos nossos encontros, nossas conversas?

Em nossa atividade de pesquisador, por mais que tentemos habitar outro modo de existir, ainda guardamos modos instituídos de ser. Apesar de toda a cautela para produzir o processo de pesquisa, é preciso analisar a postura de pesquisador-cartógrafo e autorizar-se a estar na cena de outro modo.

Ao andarmos de um lado a outro, costuramos relações com o ambiente, com as pessoas, com os lugares, numa rede de ligações que se constitui fora dos espaços usualmente denominados "rede de atenção". A noção de cuidador parece mesmo atravessar a todos.

Nesse percurso, outras perguntas se fizeram presentes. De um lado: o que chamamos "rede de atenção"? A quantidade de serviços disponíveis? A relação de 
profissionais entre um e outro serviço? E de outro: até que ponto conseguimos abrir mão de ocupar o lugar de cuidador? Será que conseguimos apostar que essa noção pode circular para além dos serviços da saúde?

\section{Cena 3}

Chegamos ao supermercado. Para alguns, o lugar é de consumo, para outros, ambiente de trabalho. Mas nesse contexto o uso foi outro. Ao entrar no estabelecimento, fomos recebidos com exclamações: "Olá!"; "Está sumido!". Entre um cumprimento e outro - "Bom dia!" - pode-se perceber a familiaridade com que se circula no espaço: "Vai lá, tomar uma água!". Havia no supermercado um bebedouro. $\mathrm{O}$ dia estava quente e a água era bem-vinda. Alguém apanhou na prateleira um copo que estava próximo e antes mesmo de começar a enchê-lo com água, ouviu-se um comentário: "Lava o copo antes!".

Depois de refrescar-se com a água, uma pequena parada no balcão do frigorífico. Em frente, há uma televisão, e próximo a ela há uma máquina de café. "Vai tomar um cafezinho agora?" - ouvimos, apesar de a moça do café não se encontrar no local para servir. Junto à máquina, dois cartazes com letras bem desenhadas e grandes. Um deles, colado na própria máquina, dizia: "Favor não mexer!". O outro, na parede, anunciava: "Dia Internacional do Café, 24 de maio, sinta-se bem com o café Meridiano!". Retirou-se um copinho de plástico e serviu-se o café: "Você quer?". Antes de sair, paramos na sessão de perfumaria para conferir o perfume de um desodorante. "Fala, meu! Tudo bom?"; "Tchau!".

Ali um supermercado transformou-se em algo mais, não era só um supermercado! As gôndolas disponibilizavam produtos. $\mathrm{O}$ frigorífico, que produz um ambiente gelado para todos os lados, parecia um grande condicionador de ar. O café, disponível para apreciação do freguês como chamariz para o consumo, foi saboreado gratuitamente depois de uma longa caminhada. Os funcionários, que muitas vezes se mantêm na discrição e no anonimato, organizando e repondo os produtos para o frenesi do consumo, surgiram como anfitriões.

Não nos interessou o consumo, mas os questionamentos disparados a partir desses acontecimentos: como usamos os espaços? Que outros usos são possíveis? Até que ponto compramos as ideias que nos são vendidas e as aceitamos como dadas e inquestionáveis?

\section{Experiência clínica}

Os acontecimentos podem disparar pensamentos e ideias. Os encontros e desencontros, as conexões e reconexões tanto impulsionam quanto paralisam. Contudo, é preciso considerar que os acontecimentos são da ordem do previsível e do imprevisível. "E, frente a qualquer uma dessas coisas, precisamos nos mover" (Machado, 2008a, p. 59).

$\mathrm{O}$ que temos feito de nossos encontros, dos encontros da vida? Que palavras produzimos? Que cenas criamos? As experiências produzidas nesse processo nos fizeram refletir sobre o quanto intervimos com a nossa presença, o quanto somos afetados pelo que está à nossa volta e o quanto podemos criar a partir de situações cotidianas. E ainda, pensamos até que ponto é possível transformar um percurso, dando a ele outros sentidos, outros tons, passos, ritmos e sons, ou seja, deparando-nos com o processo.

No âmbito da saúde mental, é comum entre nós, profissionais e técnicos, ocuparmos o lugar daquele que cuida. Muitas vezes atuamos nas funções prescritas sem nos dar conta de que aquele que "recebe" o cuidado também traz consigo noções de cuidado, de atenção e muitas outras.

Forçamo-nos a pensar em como conseguir "visitar" outros territórios existenciais sem salientar os julgamentos de nossas próprias referências. O território é "o conjunto dos projetos e das representações nos quais vai desembocar, pragmaticamente, toda uma série de comportamentos, de investimentos, nos tempos e nos espaços sociais, culturais, estéticos, cognitivos" (Guattari \& Rolnik, 2005, p. 388).

As cenas do supermercado trouxeram à tona aspectos de outro modo de uso de um lugar inóspito. Era um supermercado e ao mesmo tempo não o era... Até que ponto estamos abertos para questionar nossos territórios subjetivos? Entendemos que a clínica provoca a alteridade e pode nos pôr frente a frente com nossas intolerâncias e indiferenças ao que difere. "É importante podermos mergulhar nas intensidades da nossa época e transformar a experiência desse mergulho em ferramenta de trabalho" (Machado \& Lavrador, 2007, p. 84).

A clínica, imbricada com as ferramentas e tecnologias de nossa época, pode funcionar como dispositivo, envolvendo outras áreas que possibilitem um pensamento afirmativo e ponderando a "construção de uma clínica que inclua outras formas de expressão para além da representação" (Rauter, 1998, p. 117).

Durante uma das caminhadas irrompeu o comentário inusitado - "Eles me chamam de Robocop!". Não interessava, nesse contexto, resgatar os fatos para explicar o que havia ocorrido. O jeito de andar criou outras histórias, que parecem falar da conexão com algumas pessoas do bairro. Não se tratou de uma queixa em relação ao apelido, nem mesmo de um autoelogio. Algo havia sido recriado, o não-dito ou o fato esquecido não era mesmo para ser lembrado. 
No processo de desconstrução manicomial, é preciso apostar nas mudanças subjetivas quando os pacientes saem dos hospitais psiquiátricos. A subjetivação está na vida e sua produção perpassa tudo e todos. Pensamos as subjetividades a partir da perspectiva proposta por Foucault, Guattari e Deleuze. O processo de subjetivação rompe com os dualismos clássicos sujeito-objeto, corpo-alma e individual-social, afirmando que essa subjetivação "resulta de um entrecruzamento de determinações coletivas de várias espécies, não só sociais, mas econômicas, tecnológicas, de mídia e tantas outras" (Guattari \& Rolnik, 2005, p. 43).

Fazer andar e interagir com a cidade e as pessoas, movimentar aqueles que permaneceram internos durante anos, cronificados pela psiquiatrização, tornou-se uma das estratégias clínicas; "a relação da loucura com a cidade, com sua cultura e com a política" (Lancetti, 2006, p. 22) vem sofrendo modificações.

As experiências clínicas e os serviços são convocados a ocupar as ruas, e o espaço clínico também passa por mudanças: "Porque a clínica não é só teoria, não é só método, não é só técnica, e não é uma aplicação dos preceitos codificados de nenhuma corporação. ... A clínica é o espaço epistemológico da 'criação', da "invenção"” (Baremblitt \& Baggio, 1995, p. 36). Os profissionais de saúde mental são forçados a criar outras estratégias clínicas. Para tanto, é preciso que se reinventem e estejam mais atentos à vida.

Contudo, é preciso pensar sobre o que temos feito, pois não se trata de uma criação aleatória. "Como não existe prescrição para a invenção, o clínico deve partir da liberdade de criar em colaboração com o usuário" (Baremblitt \& Baggio, 1995, p. 36). Não estamos para "definir-lhes uma identidade, atribuir-lhes um lugar, direitos, reconhecimento, até mesmo privilégios, [e] torná-los inofensivos, esvaziando seu potencial de desterritorialização" (Pelbart, 1993, p. 104).

Nas artes, a criação se dá de variadas maneiras. No entanto, aqui nos referimos à criação ou realização de uma obra, como processo que confere a realização de todos os passos necessários para que o artista alcance uma ideia apurada dessa obra, visto que "não é depois de ter chegado a tal ideia que ele passa a realização da obra, pois ele só chega a conceber plenamente esta ideia ao longo do processo de criação que realiza a obra, pouco a pouco" (Silva, 1997, p. 212). E, quando essa ideia se apresenta, algo se desloca, produzindo ruptura com o que está cristalizado. Ou seja, algo é tirado do lugar e põe a pensar, gostando-se ou não, entendendo-se ou não.

É preciso considerar que algo sai do lugar e não se tem o entendimento imediato do que foi afetado. Temos um campo de tensão e autorizamo-nos ou não a criar uma saída, um sentido para a experiência. Ao sair de um espaço conhecido para outro desconhecido, procura-se um território, ou seja, um lugar onde se sentir melhor. Ao sair do território, ao mesmo tempo, exerce-se um esforço para se reterritorializar em outra parte.

Ao andarmos pelas ruas, estamos expostos às suas transformações, afetando-as e sendo afetados por sua pluralidade, exercitando uma liberdade para além do deslocamento físico e geográfico, o que pode provocar em nós um aumento da potência de agir, mesmo correndo perigos e sujeitando-nos à tensão que a cidade nos oferece.

Usar a cidade como lugar de intervenção faz emergir uma multiplicidade de acontecimentos, para além da rede de atenção. Na experiência com os Dispositivos-Casa temos percebido a importância desse meio do caminho: "É preciso a rua. Não basta a casa. Não basta o sossego da rede que embala. É preciso a rede que tece os laços sociais perdidos. E isto significa a cidade, com todos os seus riscos e conflitos" (Guarido \& Campos, 2006, p. 147).

A mudança de paradigma na reforma psiquiátrica rompe com o dualismo doença-solução e busca problematizar, criar e pensar outros modos no trato com a loucura. Em nossa experiência cartográfica, "não se trata de busca de uma origem, mas de uma avaliação dos deslocamentos" (Deleuze, 1992, p.75).

Quando estivemos no supermercado, desprendemo-nos do lugar do consumo, das ofertas, dos produtos e percebemos outra coisa naquele ambiente de circulação acelerada de pessoas e bens: houve uma rede de conexões, o deslocamento de códigos e a recusa de certa representatividade. Saber para que serve um supermercado não impede que criemos outros sentidos para ele. O supermercado não foi tratado como tal, mas isso não quer dizer que não se tratasse de um supermercado.

Do mesmo modo, durante o processo cartográfico a noção de cuidador pode circular. Histórias surgiram e outras foram (re) criadas. E assistir às imagens nos serviu, além de registro-intervenção, para disparar ideias e discussões, para contar ou não história, para produzir ou não outras histórias, para (re) criar histórias. Diante do vídeo e da tela da TV, escutamos: "Eu não estou andando mais desse jeito. Eu estou caminhando todos os dias e esse jeito de andar melhorou".

\section{Saídas possíveis}

Ao questionarmos o que conhecemos dos efeitos de um acontecimento, constatamos "um complexo encontro de corpos [e] os efeitos são impossíveis de entender e de acionar sem considerar suas duas vertentes" (Baremblitt \& Baggio, 1995, p. 34). Nesse contexto, entendemos corpos segundo Deleuze, ao ler Espinosa: "Um corpo pode ser qualquer coisa, pode ser um animal, pode ser um corpo sonoro, pode ser uma 
alma ou uma ideia, pode ser um corpus lingüístico, pode ser um corpo social, uma coletividade." (Deleuze, 2002, p. 132). A multiplicidade de forças se entrecruza, forjando conexões. Um instante é atravessado por sonhos, devaneios, coisas possíveis e concretas.

"A irrupção de um acontecimento nos convoca a criar figuras que venham dar corpo e sentido para a arregimentação de diferenças que ele promove" (Rolnik, 1995, p. 1). É no limite da experiência que somos provocados a pensar mais além, e é nesse limite que se podem criar bifurcações e construir outros modos de existência ou estilos de vida (Deleuze, 1992).

Os efeitos do Dispositivo-Casa/saída/filmagem refletiram tanto nos moradores das Casas e da comunidade quanto no pesquisador-cartógrafo. Pensar a experiência e ao mesmo tempo não a preservar permite considerar que algumas cenas podem ser esquecidas, enquanto outras alcançam sentidos diversos.

Vale dizer que as saídas registradas pela filmadora são diferentes das realizadas no cotidiano, devido à intervenção. O que fica à mostra nesta pesquisa são as redes de relações que os moradores vêm construindo desde a mudança de endereço, as conexões ou reconexões com o ambiente da cidade que trazem à tona a potência da vida, bem como as saídas espirituosas. Podemos afirmar que a rede ganha ramificações e se amplia para além dos serviços e do que usualmente chamamos de rede de atenção. É preciso mesmo ampliar essa noção de rede, pois do contrário ela pode soar como espaço delimitado de circulação: da Casa para os Serviços de atenção, e destes para aquela.

Ao acompanharmos o ir e vir dos moradores, realizamos os trajetos que eles foram construindo ao habitar o bairro. Nossa contribuição, como atores nesse cenário, é não só andar ao lado como também apostar na construção de outros vínculos, que passam não só por nós, profissionais e técnicos, mas também por moradores da comunidade, que nela agem. Ao andarmos juntos, a aposta é fazer ver que se constrói outra imagem da loucura, e é nesse sentido que insistimos em perguntar: "Cuidadores, quem somos?".

É necessário considerar que a potencialização da Reforma Psiquiátrica deve vir acompanhada por um processo de desconstrução do pensamento, ou seja, de modificação do conceito de loucura. É na realização de novas possibilidades de existência e, ao mesmo tempo, no uso de instrumentos e tecnologias fortes o bastante para desmistificar a loucura junto à sociedade que se podem criar rupturas ou bifurcações nos processos de subjetividades dominantes.

\section{Notas}

Fonte: Área Técnica de Saúde Mental/DAPES/SAS/MS. Conferir em http://portal.saude.gov.br/portal/arquivos/pdf/ srt_junho2010.pdf

2 Hecceidades: Programa de Pesquisa-Intervenção em Saúde Mental, da UFES, é composto de vários projetos, dentre eles o Projeto de Extensão Hecceidades, o Projeto de Pesquisa em Políticas Públicas em Saúde Mental e o Laboratório de Subjetividade e Imagens (LIS). O programa está sob a coordenação da Prof. ${ }^{\mathrm{a}}$ Dr. ${ }^{\mathrm{a}}$ Leila Domingues Machado e da Prof. ${ }^{\mathrm{a}}$ Dr. ${ }^{\mathrm{a}}$ Maria Cristina Campello Lavrador. Integram-se ao programa os graduandos do curso de Psicologia e pós-graduandos do Mestrado em Psicologia Institucional, ambos da UFES.

3 O projeto terapêutico implica que a equipe do CAPS e o usuário do serviço combinem as atividades e a frequência de participação nas atividades do serviço, que pode passar por avaliação periódica (Ministério da Saúde, 2004).

4 Sobre essa discussão conferir Passos, Kastrup e Escóssia (2009).

5 As cenas descritas compõem o processo da pesquisa e não estão diretamente relacionados ao vídeo produzido.

6 Quando foram instituídos os Serviços Residenciais Terapêuticos pela Portaria GM/MS n ${ }^{\circ} 106$, de 11 de fevereiro de 2000, entre outros aspectos foi considerada a "necessidade de acompanhar e controlar a assistência prestada aos pacientes nas residências terapêuticas" e para tanto se incluiu na Tabela de Atividade Profissional do SIA/SUS o código 47, de cuidador em saúde, conforme a Portaria/GM n ${ }^{\circ} 1.220$, de 7 de novembro de 2000 .

\section{Referências}

Amarante, P. (2003). A (clínica) e a reforma psiquiátrica. In M. Scliar \& P. D. C. Amarante (Coords.), Archivos de saúde mental e atenção psicossocial (pp. 45-65). Rio de Janeiro: NAU Editora.

Amarante, P. (2004). Saúde mental no SUS: os centros de atenção psicossocial. Brasília, DF: Ministério da Saúde.

Amarante, P. et al. (2001). Metamorfose ou invenção: notas sobre a história dos novos serviços em saúde mental no Brasil. In A. M. Jacó-Vilela, A. C. Cerezzo, \& H. B. C. Rodrigues (Orgs.), Clio-psyché hoje: fazeres e dizeres psi na história do Brasil (pp. 51-63). Rio de Janeiro: Relume Dumará/FAPERJ.

Baremblitt, G. \& Baggio, M. A. (1995). A clínica, como ela é. In A. Lancetti et al., Saúde e loucura: a clínica como ela é (pp. 31-41). São Paulo: HUCITEC.

Caiafa, J. (2005). Produção comunicativa e experiência urbana. In Anais, 28 Congresso Brasileiro da Ciência da Comunicação. Rio de Janeiro: INTERCOM. Acesso em 30 de abril, 2010, em http://www.intercom.org.br/papers/nacionais/2005/ resumos/R1589-1.pdf

Deleuze, G. (1992). Conversações. Rio de Janeiro: Ed. 34.

Deleuze, G. (2002). Espinosa: filosofia prática. São Paulo: Escuta.

Guarido, E. L. \& Campos, F. C. B. (2006). Sentir-se em casa no olho da rua: o desafio das moradias. Cadernos IPUB, 22, 141-148.

Guattari, F. \& Rolnik, S. (2005). Micropolitica: cartografias do desejo. Petrópolis, RJ: Vozes.

Houaiss, A. (2004). Minidicionário Houaiss da língua portuguesa. Rio de Janeiro: Objetiva.

Houaiss, A. \& Villar, M. de S. (2001). Dicionário eletrônico Houaiss da lingua portuguesa. Rio de Janeiro: Objetiva. 
Lancetti, A. (2006). Clínica peripatética. São Paulo: HUCITEC.

Lavrador, M. C. C. (2006). Loucura e vida na contemporaneidade. Tese de Doutorado, Universidade Federal do Espírito Santo, Espírito Santo, Brasil.

Machado, L. D. (2008a). O que chamamos clínica? In E. M. Rosa (Org.), A produção da psicologia social no Espírito Santo: memórias, interfaces e compromissos (pp. 59-69). Vitória: UFES/ABRAPSO.

Machado, L. D. (2008b, janeiro/junho). Imagens da subjetividade. Informática na educação: teoria \& prática, 11(1), 47-55.

Machado, L. D. \& Lavrador, M. C. C. (2007). Subjetividade e loucura: saberes e fazeres em processo. Revista Vivência, 32, 79-95.

Ministério da Saúde (2004). Saúde mental no SUS: os centros de atenção psicossocial. Brasília: autor.

Passos, E., Kastrup, V., \& Escóssia, L. (2009). Pistas do método da cartografia: pesquisa-intervenção e produção da subjetividade. Porto Alegre: Sulina.

Pelbart, P. P. (1993). A nau do tempo-rei: sete ensaios sobre o tempo da loucura. Rio de Janeiro: Imago.

Portaria n. 106, de 11 de fevereiro de 2000. (2000). Institui os Serviços Residenciais Terapêuticos. Acesso em 10 de abril, 2010, em http://dt2004.saude.gov.br/susdeaz/legislacao/ arquivo/27_Portaria_106_de_11_02_2000.pdf

Portaria n. 1.2220, de 07 de novembro de 2000. (2000). Criação do Serviço Residencial Terapêutico em Saúde Mental, da atividade profissional Cuidador em Saúde, o grupo de procedimentos Acompanhamento de Pacientes e o subgrupo Acompanhamento de Pacientes Psiquiátricos, o procedimento Residência Terapêutica em Saúde Mental, dentre outros. Acesso em 10 de abril, 2010, em http://portal.saude.gov.br/portal/ saude/cidadao/visualizar texto.cfm?idtxt $=23120$

Rauter, C. (1998). Clínica do esquecimento: construção de uma superficie. Tese de Doutorado, Pontifícia Universidade Católica de São Paulo, São Paulo, Brasil.

Rolnik, S. (1995). O mal-estar na diferença. Núcleo de Estudos da Subjetividade da PUC-SP. Acesso em 30 de abril, 2010, em
http://www.pucsp.br/nucleodesubjetividade/Textos/SUELY/ Malestardiferenca.pdf

Rotelli, F., Leonardis, O., \& Mauri, D. (1990). Desinstitucionalização, uma outra via. In F. Nicácio (Org.), Desinstitucionalização (pp. 17-59). São Paulo: HUCITEC.

Silva, A. E. (1997). Voltar as costas para o tempo: o problema da subjetividade em Bergson. In A. E. Silva, C. A. B. Neves, C. Rauter, E. Passos, R. B. Barros, \& S. C. Josephson (Orgs.), Saúde loucura 6: Subjetividade: questões contemporâneas (pp. 208-220). São Paulo: HUCITEC.

Yasui, S. (1989). CAPS: Aprendendo a perguntar. In A. Lancetti, Saúde loucura 1 (pp. 47-89). São Paulo: HUCITEC.

Recebido em: 05/05/2010

Revisão em: 07/09/2010

Aceite em: 18/01/2011

Janayna Araújo Costa Pinheiro é Psicóloga, mestre em Psicologia Institucional pela Universidade Federal do Espírito Santo. Email: janayna.araujo@gmail.com

Leila Domingues Machado é Professora do Departamento de Psicologia e do Programa de Pós-Graduação em Psicologia Institucional da Universidade Federal do Espírito Santo. Endereço: Av. Fernando Ferrari, 514, Goiabeiras. Vitória/ ES, Brasil. CEP 29075-910. Email: leiladomingues@uol.com.br

\section{Como citar:}

Pinheiro, J. A. C. \& Machado, L. D. (2011). Experiência clínica por meio de imagens cartográficas. Psicologia \& Sociedade, 23(n. spe.), 120-128. 